\title{
Diagnostic and predictive accuracy of anti-mullerian hormone for ovarian function after chemotherapy in premenopausal women with early breast cancer
}

\author{
Richard A. Anderson ${ }^{1}$ D $\cdot$ Tom W. Kelsey ${ }^{2} \cdot$ Anne Perdrix $^{3,4} \cdot$ Nathalie Olympios $^{5} \cdot$ Orianne Duhamel $^{5}$. \\ Matteo Lambertini ${ }^{6,7}$. Florian Clatot $^{4,5}$
}

Received: 18 November 2021 / Accepted: 30 December 2021 / Published online: 8 January 2022

(C) The Author(s) 2022

\begin{abstract}
Purpose Accurate diagnosis and prediction of loss of ovarian function after chemotherapy for premenopausal women with early breast cancer $(\mathrm{eBC})$ is important for future fertility and clinical decisions regarding the need for subsequent adjuvant ovarian suppression. We have investigated the value of anti-mullerian hormone (AMH) as serum biomarker for this.

Methods AMH was measured in serial blood samples from 206 premenopausal women aged 40-45 years with eBC, before and at intervals after chemotherapy. The diagnostic accuracy of AMH for loss of ovarian function at 30 months after chemotherapy and the predictive value for that of AMH measurement at 6 months were analysed.

Results Undetectable AMH showed a high diagnostic accuracy for absent ovarian function at 30 months with AUROC 0.89 (96\% CI 0.84-0.94, $P<0.0001$ ). PPV of undetectable AMH at 6 months for a menopausal estradiol level at 30 months was 0.77. In multivariate analysis age, pre-treatment $\mathrm{AMH}$ and $\mathrm{FSH}$, and taxane treatment were significant predictors, and combined with AMH at 6 months, gave AUROC of 0.90 (95\% CI 0.86-0.94), with PPV 0.79 for loss of ovarian function at 30 months. Validation by random forest models with $30 \%$ data retained gave similar results.

Conclusions AMH is a reliable diagnostic test for lack of ovarian function after chemotherapy in women aged 40-45 with eBC. Early analysis of AMH after chemotherapy allows identification of women who will not recover ovarian function with good accuracy. These analyses will help inform treatment decisions regarding adjuvant endocrine therapy in women who were premenopausal before starting chemotherapy.
\end{abstract}

Keywords Breast cancer $\cdot$ Biomarker $\cdot$ Anti-mullerian hormone $\cdot$ Ovarian function $\cdot$ Predictive testing

Richard A. Anderson

Richard.anderson@ed.ac.uk

Tom W. Kelsey

twk@st-andrews.ac.uk

Anne Perdrix

anne.perdrix@chb.unicancer.fr

Nathalie Olympios

nathalie.olympios@chb.unicancer.fr

Orianne Duhamel

orianne.duhamel@chb.unicancer.fr

Matteo Lambertini

matteo.lambertini@unige.it

Florian Clatot

florian.clatot@chb.unicancer.fr

MRC Centre for Reproductive Health, Queens Medical

Research Institute, University of Edinburgh, 47 Little France

Crescent, Edinburgh EH16 4TJ, UK
2 School of Computer Science, University of St Andrews, St Andrews, UK

3 Department of Biopathology, Centre Henri Becquerel, Rouen, France

4 Normandie Univ, UNIROUEN, Inserm U1245, Rouen, France

5 Department of Medical Oncology, Centre Henri Becquerel, Rouen, France

6 Department of Internal Medicine and Medical Specialties (DiMI), School of Medicine, University of Genova, Genoa, Italy

7 Department of Medical Oncology, U.O.C. Clinica di Oncologia Medica, IRCCS Ospedale Policlinico San Martino, Genoa, Italy 


\section{Introduction}

The treatment of early breast cancer (eBC) frequently includes multi-agent chemotherapy; adjuvant endocrine therapy is also widely used in case of hormone receptorpositive tumour $(\mathrm{HR}+)$ to suppress the effect of remaining estrogen production and reduce the risk of relapse [1]. Extensive research has demonstrated the superiority of aromatase inhibitors (AIs) over tamoxifen as adjuvant endocrine therapy for postmenopausal eBC [2]. While AIs alone are ineffective in premenopausal women [3, 4], when co-administered with a gonadotropin releasinghormone agonist (GnRHa), they achieve therapeutically adequate suppression of serum estrogen levels [5]. The superiority of combining AI with ovarian suppression as adjuvant endocrine therapy in premenopausal women as compared to tamoxifen-based treatment has been recently demonstrated in the SOFT and TEXT trials [6] and in the HOBOE study [7].

Many women with eBC become amenorrhoic after chemotherapy, the proportion increasing with age $[8,9]$. As some show variable recovery, which may take 2 years or occasionally longer $[10,11]$, the diagnosis of a permanent menopausal state is often difficult. However, many women will have permanent loss of ovarian function during or shortly after chemotherapy, and accurate early identification of these women might allow optimization and simplification of the choice of adjuvant endocrine therapy [12].

The measurement of anti-Müllerian hormone (AMH) has become established as the most reliable biomarker of the number of small growing follicles in the ovary, which indirectly reflects the number of primordial follicles, i.e. the ovarian reserve [13]. AMH levels decline to undetectable at the time of the menopause [14, 15]. A substantial body of evidence has demonstrated that AMH levels fall in women during chemotherapy, with variable recovery depending on the treatment regimen [16-20], pre-treatment AMH levels and younger age [21-25], and possibly BMI [26]. Post-chemotherapy AMH measurement also predicts of ovarian function recovery [27-29]: if a woman with $\mathrm{eBC}$ has a very low or undetectable AMH level after chemotherapy, there is high confidence that she is indeed permanently menopausal [28]. Assessment shortly after completion of chemotherapy would aid clinical management; measurement of AMH shortly after completion of chemotherapy showed good prediction of women who would have ovarian failure at 24 months after diagnosis [27].

In this study, we investigated whether AMH measurement is a reliable method of identifying whether or not there is residual ovarian function following completion of chemotherapy in women aged 40 and over with eBC. This would potentially allow avoidance of unnecessary administration of GnRHa treatment as adjuvant endocrine therapy, with significant benefits in cost savings and in convenience to the patient.

\section{Methods}

\section{Patients}

This study was conducted within a cohort of consecutive patients with eBC diagnosed between 40 and 45 years of age who underwent (neo)adjuvant chemotherapy between January 2008 and December 2016 at the Henri Becquerel Cancer Center (Rouen, France). Of a total of 494 patients of appropriate age during that period, only patients with available stored blood samples before and at 6, 18 and 30 months after chemotherapy were included, and hormone assays were then performed. Chemotherapy was based on epirubicin, cyclophosphamide $+/-$ a taxane (docetaxel in the great majority). Adjuvant endocrine therapy consisted of tamoxifen exclusively, with no exposure to AIs or GnRH agonists.

All patients gave written informed consent allowing the conservation and study of their biological samples. The present study was approved by the Institutional Scientific and Ethics Committees of Henri Becquerel Centre (registering order $\mathrm{N}^{\circ} 1917 \mathrm{~B}$ ).

\section{Hormone analyses}

$\mathrm{AMH}$, follicle stimulating hormone (FSH) and estradiol were measured in plasma using an electrochemiluminescence autoanalyser (Elecsys ${ }^{\circledR}$ assay reagents, cobas e601 analyser, Roche Diagnostics). All samples from the same patient were analysed in the same run to minimize betweenrun variability. For AMH (Elecsys AMH Plus), the limit of detection (LOD) is $0.01 \mathrm{ng} / \mathrm{mL}(0.07 \mathrm{pmol} / \mathrm{L})$ and limit of quantification (LOQ) $0.03 \mathrm{ng} / \mathrm{L}$. The between-run variability was $1.13 \%$ at $0.929 \mathrm{ng} / \mathrm{mL}$, and $1.3 \%$ at $4.86 \mathrm{ng} / \mathrm{mL}$. The estradiol assay (Elecsys Estradiol III) LOD is $18.4 \mathrm{pmol} / \mathrm{L}$ $(5 \mathrm{pg} / \mathrm{mL})$ and LOQ is $91.8 \mathrm{pmol} / \mathrm{L}$. The FSH assay (Elecsys FSH) LOD is $<0.1 \mathrm{IU} / \mathrm{L}$.

\section{Statistical methods}

Data are presented as median and $95 \%$ confidence interval (CI). Changes in hormone concentrations over time were analysed by repeat measures ANOVA with Bonferroni correction for multiple comparisons. Receiver-operator characteristic (ROC) curve analyses were performed, reporting area under the curve (AUROC). Univariate analysis investigated simple relationships between detectable and undetectable 
$\mathrm{AMH}$ as binary category and later ovarian function as a binary category defined by a threshold level.

Multivariate analysis was also performed to assess the predictive performance of baseline and treatment characteristics (endocrine and non-endocrine) and post-chemotherapy endocrine factors in terms of later ovarian function. Multivariate analysis was performed in three stages. First, individual variables were assessed for prediction of undetectable AMH at 30 months' post-treatment. Second, suitable candidate variables from the first stage were used in multivariate linear regression models (PRISM version 9, GraphPad Software LLC, San Diego USA) to provide estimates of AUROC, PPV and NPV. Third, and to guard against the multivariate linear regression models over- or underfitting the data (i.e. supplying estimates that are unlikely to generalize to new data instances) a full machine learning workflow was performed using scikit-learn version 0.46 within Python version 3.9.2. The workflow stages were: shuffling and splitting data into $70 \%$ train and $30 \%$ validation subsets; fivefold cross-validated grid search of 420 options for optimal hyperparameters for the random forest algorithm applied to the test data; cross-validated application of the optimal model on the training data; application of the model to the validation data subset that mimics new data instances. A linear regression model was considered validated in terms of clinical utility if (a) the cross-validated test performance of the random forest model for the test data was close to the validation performance (i.e. the model is neither overnor-underfitting the data), and (b) the validation AUROC is similar to the estimate found by linear regression.

\section{Results}

Samples from a total of 206 women were analysed, with complete sample sets in 197 women. Most (76\%) patients had HR+ disease and received tamoxifen; 48 patients had HR- tumours and did not receive adjuvant endocrine treatment. Chemotherapy regimens were based on 6 cycles of cyclophosphamide with an anthracycline, and the addition of a taxane in $84 \% ; 22 \%$ received anti-HER 2 targeted therapy. Six patients received 8 cycles of chemotherapy in the context of inflammatory breast carcinoma. Among the 173 patients exposed to a taxane, all but 3 were received docetaxel. Patient characteristics, tumour and treatment details are described in Table 1.

AMH concentrations fell markedly following chemotherapy from a median of 0.62 (IQR $0.21-1.31$ ) $\mathrm{ng} / \mathrm{ml}$ at baseline becoming undetectable in 137 (70\%) of 197 women at 6 months (Fig. 1) and with very little recovery thereafter $(P<0.001$ vs pre-treatment at all time points). AMH was undetectable in $115(58 \%)$ and $119(60 \%)$ women at 18 and 30 months respectively. There was a rise in FSH from 6.4
Table 1 Baseline characteristics of study population

\begin{tabular}{|c|c|}
\hline Patients characteristics & All patients $(N=206)$ \\
\hline Age at diagnosis, mean (SD) & $42.76(1.76)$ \\
\hline Weight (kg), mean (SD) & $67.54(14.57)$ \\
\hline Body mass index $\left(\mathrm{kg} / \mathrm{m}^{2}\right)$, mean (SD) & $25.12(5.29)$ \\
\hline Smoker, $N(\%)$ & $72(35 \%)$ \\
\hline Genetic mutation, $N(\%)$ & $14(6.8 \%)$ \\
\hline BRCA1 & $9(64 \%)$ \\
\hline BRCA2 & $5(36 \%)$ \\
\hline \multicolumn{2}{|l|}{ Tumour characteristics, $N(\%)$} \\
\hline \multicolumn{2}{|l|}{ Histological grade } \\
\hline Grade I & $9(4.4 \%)$ \\
\hline Grade II & $93(45.1 \%)$ \\
\hline Grade III & $104(50.5 \%)$ \\
\hline Hormone Receptor positivity & $162(78.6 \%)$ \\
\hline Oestrogen receptor & $161(78.2 \%)$ \\
\hline Progesterone receptor & $140(68 \%)$ \\
\hline HER2 positive & $47(22.8 \%)$ \\
\hline Triple negative & $32(15.5 \%)$ \\
\hline Pathological nodal status positivity & $119(57.8 \%)$ \\
\hline \multicolumn{2}{|l|}{ Tumour size $(\mathrm{T})$} \\
\hline $\mathrm{T} 1$ & $91(44.2 \%)$ \\
\hline $\mathrm{T} 2$ & $91(44.2 \%)$ \\
\hline $\mathrm{T} 3$ & $19(9.2 \%)$ \\
\hline $\mathrm{T} 4 \mathrm{a}$ & $1(0.5 \%)$ \\
\hline $\mathrm{T} 4 \mathrm{~b}$ & $1(0.5 \%)$ \\
\hline $\mathrm{T} 4 \mathrm{~d}$ & $3(1.5 \%)$ \\
\hline \multicolumn{2}{|l|}{ Surgical treatment, $N(\%)$} \\
\hline Conservative & $128(62.1 \%)$ \\
\hline Mastectomy & $78(37.8 \%)$ \\
\hline \multicolumn{2}{|l|}{ Adjuvant or neoadjuvant treatment, $N(\%)$} \\
\hline Radiation therapy & $200(97.1 \%)$ \\
\hline Endocrine therapy & $160(77.7 \%)$ \\
\hline Chemotherapy & $206(100 \%)$ \\
\hline \multicolumn{2}{|l|}{ Chemotherapy regimen, $N(\%)$} \\
\hline With taxane & $173(84 \%)$ \\
\hline Without taxane & $33(16 \%)$ \\
\hline With HER2 inhibitor & $46(22 \%)$ \\
\hline \multicolumn{2}{|l|}{ Fertility history, $N(\%)$} \\
\hline Pregnancy before treatment & $182(88.3 \%)$ \\
\hline
\end{tabular}

(IQR 0.2-1.3) IU/L at baseline to 30.6 (IQR 18.2-47.1) IU/L at 30 months $(P<0.001$ vs baseline at all time points), and a sustained fall in estradiol from 285 (IQR 168-2095) pmol/L at baseline to 65.6 (IQR 45.2-4111) pmol/L at 30 months (Fig. $1 \mathrm{~b}$ and c).

The value of AMH as an index and as a predictor of absent ovarian function after recovery from chemotherapy was explored. At 30 months, women with undetectable AMH at that time $(n=119)$ had median estradiol of $50 \mathrm{pmol} / \mathrm{L}$ (IQR 34-68), whereas it was $313 \mathrm{pmol} / \mathrm{L}$ (IQR 

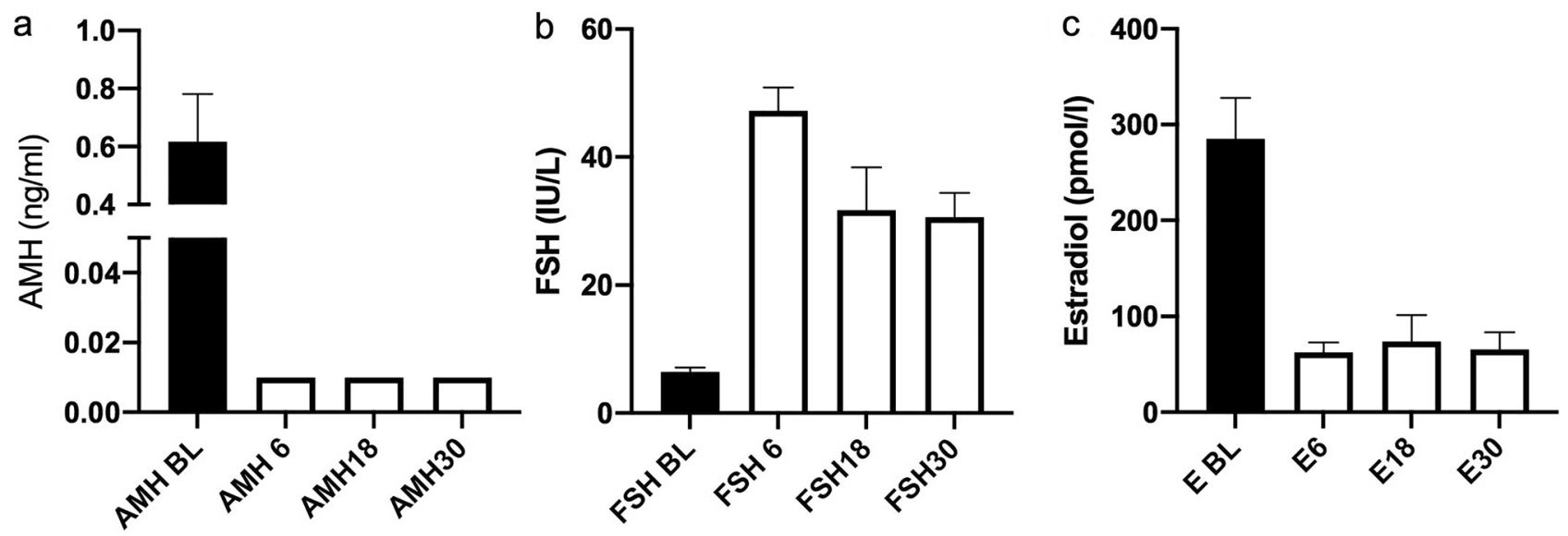

Fig. 1 AMH (a), FSH (b) and estradiol (c) concentrations pre-treatment and at 6, 18 and 30 months after completing chemotherapy for eBC. Median $\pm 95 \%$ CI, $N=206$

102-1052) $(P<0.0001)$ in the 80 women with detectable AMH (Fig. 2a). Thus, undetectable AMH at 30 months showed a high diagnostic accuracy for absent ovarian function with AUROC 0.89 (96\% CI 0.84-0.94, $P<0.0001$; Fig. 2b), with peak likelihood ratio of 25.3 at an estradiol concentration of $38.1 \mathrm{pmol} / \mathrm{L}$, with sensitivity $29 \%$ and specificity $98.8 \%$. This demonstrated that after recovery from chemotherapy, undetectable AMH was an accurate diagnostic test of absent ovarian activity, and therefore it was used as an outcome measure for multivariate predictive analyses, supporting analysis of estradiol levels.

For prediction of later ovarian activity, women with undetectable $\mathrm{AMH}$ at 6 months $(N=137)$ had median estradiol levels at 30 months of $56 \mathrm{pmol} / \mathrm{L}$ (IQR 40-104), vs $258 \mathrm{pmol} / \mathrm{L}$ (IQR 69-780) $(P<0.0001)$ in women with detectable AMH at 6 months $(n=62)$ (Fig. 2a). AUROC for estradiol at 30 months by undetectable AMH at 6 months was 0.75 (95\% CI $0.67-0.82, P<0.0001$; Fig. 2c), with sensitivity $19.7 \%$ and specificity $95.1 \%$ at estradiol concentration of $34.4 \mathrm{pmol} / \mathrm{L}$, at which likelihood ratio peaked at 4.0. The positive predictive value of undetectable $\mathrm{AMH}$ at 6 months for a menopausal estradiol level $(<110 \mathrm{pmol} / \mathrm{L}$ [30]) at 30 months was 0.77. Supporting this, AMH at 6 months for prediction of undetectable $\mathrm{AMH}$ at 30 months was explored. AUROC was 0.76 (CI 0.68-0.83, $P<0.0001$ ), with PPV of undetectable AMH at 6 months for unpredictable AMH at 30 months of 0.78 .

As both FSH and estradiol may be impacted by tamoxifen treatment, data were additionally analysed separately in the 48 women not taking tamoxifen. AMH was undetectable in $29(60 \%)$ of these women at 6 months, and also in $29(60 \%)$ women at 30 months. At 30 months, median estradiol concentrations of women grouped by detectable vs undetectable AMH levels at both 30 and 6 months (Fig. 2d) were similar to those groups in the whole cohort of women (Fig. 2a).
ROC analysis demonstrated the very high predictive value of undetectable vs detectable AMH at 30 months for estradiol at 30 months, AUROC 0.95 (0.89-1.00, $P<0.0001$; Fig. 2e); similarly, AMH at 6 months was predictive of estradiol at 30 months, with AUROC $0.79(0.66-0.92, P=0.001)$ (Fig. 2f).

FSH is an established diagnostic test for POI, thus analyses were performed in women not taking tamoxifen for $\mathrm{AMH}$ as a predictor of $\mathrm{FSH}>25 \mathrm{IU} / \mathrm{L}$. At 30 months, median FSH in women with undetectable AMH at that time point was $87.8 \mathrm{IU} / \mathrm{L}$ (IQR 67.7-126.9) vs $12.4 \mathrm{IU} / \mathrm{L}$ (8.6-25.2) $(P<0.0001)$ in those with detectable AMH. Analysis by AMH at 6 months gave comparable results (Fig. 2g), with median FSH at 30 months of 69.4 IU/L (42.5-108.8) vs 12.2 IU/L (8.6-23.9). The diagnostic value was assessed by ROC analysis for AMH at 30 months, showing AUROC 0.98 (0.96-1.00), and for prediction by AMH at 6 months, AUROC was $0.86(0.72-0.99)$ (both $P<0.0001$; Fig. $2 \mathrm{~h}$ and i) with peak likelihood ratio of 7.9 at $\mathrm{FSH}$ 27.7 IU/L. An undetectable AMH at 6 months had a PPV for $\mathrm{FSH}>25 \mathrm{IU} / \mathrm{L}$ at 30 months of 0.93 , indicating a very high predictive value for long-term POI after chemotherapy.

\section{Multivariate analyses}

The variables age, pre-treatment $\mathrm{AMH}$ and $\mathrm{FSH}$, and taxane treatment were found to be significant predictors of $\mathrm{AMH}$ at 30 months; BMI and pre-treatment estradiol were not (Table 2). The significant predictors were then combined with AMH at 6 months for prediction of AMH at 30 months (Table 2). This gave AUROC of 0.90 (95\% CI 0.86-0.94), with PPV 0.79 and NPV 0.79 (Fig. 3). Using estradiol at 30 months of $<110 \mathrm{pmol} / \mathrm{L}$ as the outcome, the same variables gave AUROC of 0.82 (0.76-0.90), PPV 0.68 and NPV 0.76 (Fig. 3). 
Hormone results
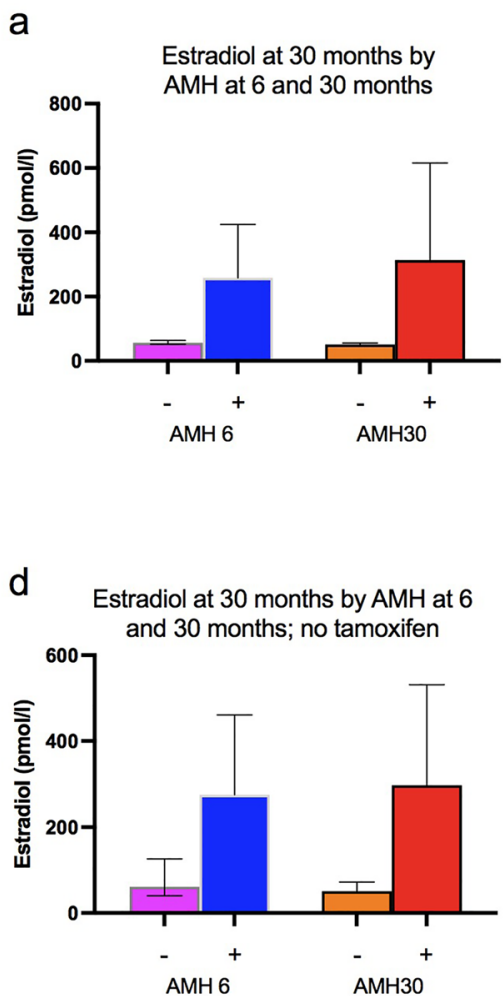

g

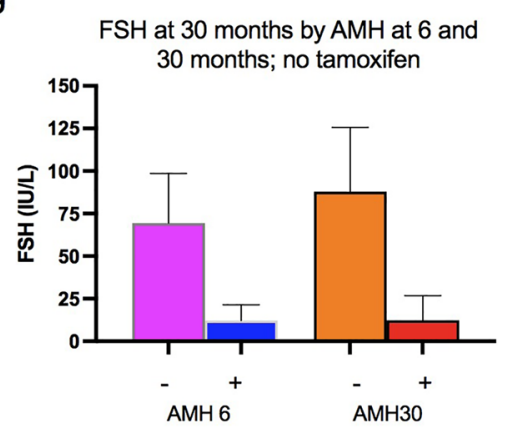

Diagnostic tests at 30 months

Predictive tests from 6 months
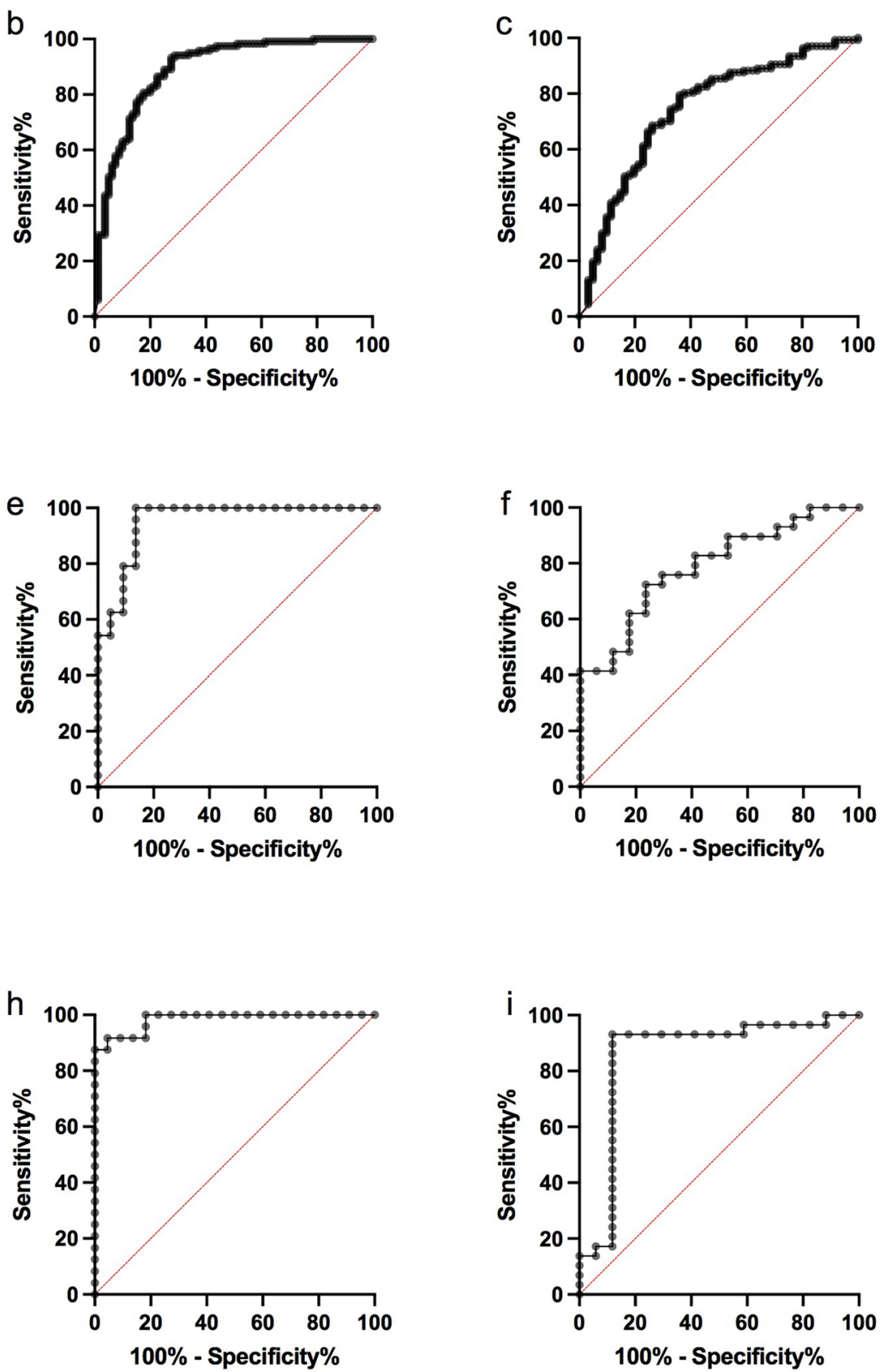

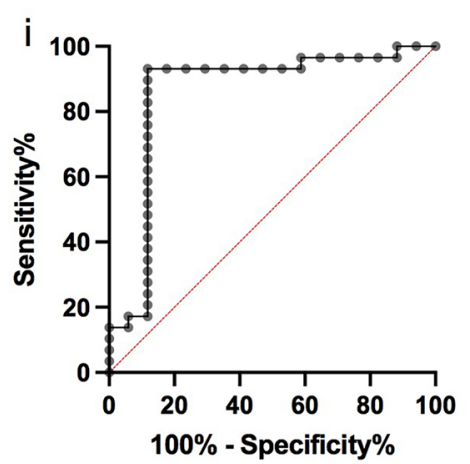

Fig. 2 Hormone results (a, d, g), results of diagnostic testing at 30 months (b, e, h) and predictive testing of 30 months by data at 6 months $(\mathbf{c}, \mathrm{f}, \mathbf{i})$. a Estradiol levels at 30 months by AMH at 6 and 30 months, divided into AMH undetectable (-) vs AMH detectable (+), with ROC curves for diagnostic analysis by AMH at 30 months (b), and prediction by AMH at 6 months (c). d In women not treated with tamoxifen: Estradiol levels at 30 months by AMH at 6 and

Two additional analyses were performed to assess prediction if pre-treatment hormone data were not available, and of pre-treatment variables (including taxane treatment) only. In the absence of pre-treatment hormone data, age/taxane treatment/AMH6 gave AUROC $0.71(0.63-0.79)$ with PPV
30 months, divided into AMH undetectable (-) vs AMH detectable (+), with ROC curves for diagnostic analysis by AMH at 30 months (e), and predictive analysis by AMH at 6 months (f). $\mathrm{g}$ In women not treated with tamoxifen: FSH levels at 30 months by AMH at 6 and 30 months, divided into AMH undetectable (-) vs AMH detectable (+), with ROC curves for diagnostic analysis by AMH at 30 months (h), and predictive analysis by AMH at 6 months (i)

0.78 and NPV 0.77. Conversely, age/taxane treatment/pretreatment hormone variables gave AUROC 0.88 (0.83-0.92), PPV 0.77 and NPV 0.79 .

The linear regression models were validated by random forest models with data retained for validation purposes, 
Table 2 Results of univariate, multivariate and random forests analysis

\begin{tabular}{|c|c|c|c|c|c|c|c|}
\hline \multicolumn{8}{|c|}{ Univariate analysis vs $\mathrm{AMH}$ at 30 months } \\
\hline \multirow{2}{*}{$\begin{array}{l}\text { Variable } \\
\text { Taxane }\end{array}$} & \multirow{2}{*}{$\frac{\mathrm{OR}}{0.70}$} & \multicolumn{6}{|l|}{$95 \% \mathrm{CI}$} \\
\hline & & \multicolumn{6}{|l|}{$0.52-0.96$} \\
\hline Age & 0.99 & \multicolumn{6}{|l|}{$0.98-0.99$} \\
\hline BMI & 1.04 & \multicolumn{6}{|l|}{$0.98-1.09$} \\
\hline BL AMH & 6.84 & \multicolumn{6}{|l|}{$3.89-13.41$} \\
\hline BL FSH & 0.92 & \multicolumn{6}{|l|}{$0.89-0.95$} \\
\hline BL estradiol & 1 & \multicolumn{6}{|l|}{$0.99-1.00$} \\
\hline \multicolumn{4}{|c|}{ Multivariate analysis vs AMH at 30 months } & AUROC & $95 \% \mathrm{CI}$ & NPV & PPV \\
\hline Age & 0.97 & $0.94-1.01$ & Multivariate & 0.90 & $0.86-0.94$ & 79.4 & 78.8 \\
\hline Taxane & 3.54 & $1.17-12.00$ & RF & 0.89 & & 71.9 & 81.6 \\
\hline BL AMH & 4.16 & $2.36-8.25$ & & & & & \\
\hline BL FSH & 0.93 & $0.84-0.99$ & & & & & \\
\hline AMH6 & 0.2 & $0.08-0.50$ & & & & & \\
\hline \multicolumn{8}{|c|}{ Multivariate vs estradiol at 30 months $<110 \mathrm{pmol} / \mathrm{L}$} \\
\hline Age & 0.98 & $0.95-1.00$ & Multivariate & 0.82 & $0.76-0.88$ & 75.5 & 68.0 \\
\hline Taxane & 1.64 & $0.66-4.42$ & $\mathrm{RF}$ & 0.76 & & 66.8 & 82.6 \\
\hline BL AMH & 2.03 & $1.45-3.01$ & & & & & \\
\hline BL FSH & 0.99 & $0.95-1.02$ & & & & & \\
\hline AMH6 & 0.36 & $0.16-0.78$ & & & & & \\
\hline \multicolumn{8}{|c|}{ If no pre-treatment hormone data vs $\mathrm{AMH}$ at 30 months } \\
\hline Age & 1.01 & $0.99-1.03$ & Multivariate & 0.71 & $0.63-0.79$ & 76.6 & 78.3 \\
\hline Taxane & 3.69 & $1.36-11.06$ & $\mathrm{RF}$ & 0.85 & & 56.3 & 92.1 \\
\hline AMH6 & 0.07 & $0.03-0.15$ & & & & & \\
\hline \multicolumn{8}{|c|}{ Pre-treatment data only } \\
\hline Age & 0.96 & $0.92-0.99$ & Multivariate & 0.88 & $0.83-0.92$ & 78.6 & 76.5 \\
\hline Taxane & 2.2 & $0.80-6.66$ & $\mathrm{RF}$ & 0.87 & & 65.6 & 84.2 \\
\hline BL AMH & 5.44 & $3.09-10.82$ & & & & & \\
\hline BL FSH & 0.91 & $0.82-0.98$ & & & & & \\
\hline
\end{tabular}

AMH6 grouped by undetectable vs detectable AMH at 6 months, $B L$ baseline (pre-treatment) sample, $R F$ random forest, $O R$ odds ratio, $A U R O C$ area under the curve of receiver-operator characteristic analysis $N P V$ negative predictive value, $P P V$ positive predictive value

with random forest AUROC within the $95 \%$ CI for the AUROC reported for the logistic regression model (Table 2). Without pre-treatment hormone data, the random forest AUROC was significantly higher at 0.85 compared to 0.71 , indicating that the linear regression model is underfitting the data. For the other analyses, the cross-validated test accuracy of each optimal random forest model was within 4.6 percentage points of the validation accuracy.

\section{Discussion}

Assessment of ovarian function after chemotherapy is critical for women with breast cancer where decisions about appropriate endocrine treatment are required [12]. Moreover, many women also want to know whether a later pregnancy might possible. There is increasing evidence for the value of AIs in women who are premenopausal at the time of diagnosis $[6,7]$, but if there is ovarian activity after chemotherapy, concomitant ovarian suppression with a $\mathrm{GnRH}$ agonist is necessary to ensure adequate suppression of estradiol levels. There is however uncertainty as to the degree of suppression of estradiol levels that is required and accuracy of immunoassays at these low concentrations [31], indicating a need for improved biomarkers of ovarian function.

In these analyses we have explored the potential accuracy of AMH as a biomarker of ovarian activity after chemotherapy for eBC, as a diagnostic test at 30 months after completion of chemotherapy (thus allowing for any recovery) and a predictive test at 6 months after chemotherapy. AMH levels 


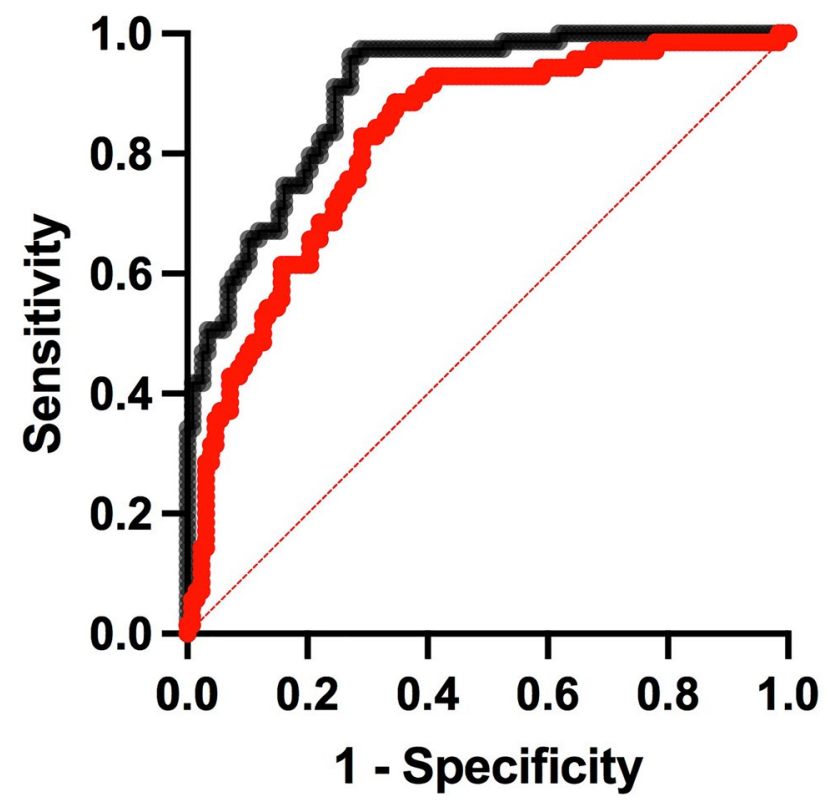

Fig. 3 Multivariate ROC analysis: prediction of undetectable AMH (black) or estradiol $<110 \mathrm{pmol} / \mathrm{L}$ (red) at 30 months by $\mathrm{AMH}$ at 6 months, pre-treatment hormone data and taxane treatment

fell dramatically after chemotherapy, with overall very little recovery thereafter, as previously reported [17-20]. Undetectable AMH at that time accurately distinguished women with low estradiol levels, indicating that AMH is a clinically useful index of ovarian function in this context. The best estradiol concentration cut-off distinguishing women with and without detectable AMH levels was $34 \mathrm{pmol} / \mathrm{L}$, similar to the upper limit in postmenopausal women using mass spectroscopy [32].

While accurate diagnosis of absent ovarian function after allowing for potential recovery is of value, it would be of yet greater clinical value to be able to predict post-treatment menopausal status at the end of chemotherapy. At 6 months after chemotherapy, thus at a clinically relevant time point to decide on whether ovarian suppression might be necessary [6, 33], AMH levels were undetectable in $70 \%$ of the population. This had clear value in predicting later ovarian function, by estradiol levels or AMH at 30 months. Thus, women aged over 40 treated for eBC with anthracycline- and taxane-based chemotherapy regimens who have an undetectable AMH level at 6 months, using a highly sensitive assay, are very likely to show permanent loss of ovarian function, and ovarian suppression may not be required. This supports a previous analysis of a smaller group of women with eBC $(n=32)$, where undetectable AMH at the end of chemotherapy accurately predicted lack of recovery of ovarian function in women aged over 40, but not younger women [27].

However, some women did show a degree of recovery of ovarian function, mostly within 18 months of chemotherapy.
This late recovery has been demonstrated previously [10, $11]$, and while more likely in younger women, the present analysis documents its prevalence in women aged $40-45$ years at approximately $11 \%$ of the population studied. While the recovery in AMH levels was small, estradiol levels in some women were high, reflecting the effect of tamoxifen treatment inducing multifollicular ovarian activity.

While cut-off levels of estradiol for diagnosis of menopausal status are debated [31], there is consensus that the biochemical diagnosis of menopause or POI should be based on FSH levels, with high levels reflecting a lack of estrogen and inhibin-mediated feedback on the hypothalamus and anterior pituitary gland. A value of $25 \mathrm{IU} / \mathrm{L}$ is widely recommended for both POI and natural menopause [34-36], although others suggest a higher value. As tamoxifen, through estrogen receptor antagonism, raises FSH levels, this can only be used in women not taking any endocrine therapy. In that group of women, our study showed that undetectable AMH levels at both 6 and 30 months were associated with similar discrimination of estradiol levels as in the whole study population, and analysis of diagnostic accuracy showed slightly greater precision for both diagnosis at 30 months and prediction at 6 months of both 30-month estradiol and AMH than in the wider group. PPV of undetectable AMH at 6 months for elevated FSH consistent with a diagnosis of POI at 30 months was a remarkable 0.93 .

While a single assay of AMH at 6 months provides good prediction of later ovarian function and has the clinical benefit of simplicity, we also explored whether additional endocrine, patient and treatment factors could improve this prediction. We and others have shown that pre-treatment AMH is predictive [21-25], as is age, with BMI also contributing in some studies [26]. The addition of a taxane to cyclophosphamide-based regimens also increases ovarian toxicity $[17,20]$. In multivariate analysis, pre-treatment AMH and taxane treatment were the most important predictors: the limited value of age is likely to reflect the narrow age range in this specific study population. Including all identified factors resulted in PPV 0.79 for prediction of undetectable $\mathrm{AMH}$ at 30 months: random forest analysis gave a similar value of 0.82 . Very similar results were obtained using estradiol at 30 months as the outcome variable. Analysis without pre-treatment hormone data gave similar results (though with an improvement in PPV to 0.92 by random forest), and by pre-treatment variables only (thus including pre-treatment AMH and taxane treatment) gave PPV of 0.77 , with again better prediction by random forest analysis with PPV 0.84. Thus, using this approach with partial data retention for validation to prevent over-fitting allows accurate prediction of long-term ovarian function from either a single post-chemotherapy AMH test alone, or supplemented by knowledge of pre-treatment $\mathrm{AMH}$ and taxane treatment, 
or indeed with similar accuracy from pre-treatment AMH and taxane treatment alone. Therefore, this has validity and utility in a range of clinical scenarios, depending on which variables are known.

\section{Conclusion}

These data demonstrate that in women aged 40-45 treated for $\mathrm{eBC}$ and after time to allow any recovery of ovarian function, an undetectable AMH level, using this assay platform, is a reliable diagnostic test for lack of ovarian function. Furthermore, early analysis of AMH after completion of chemotherapy allows identification of women who will not recover ovarian function with good accuracy. The combination of pre-treatment AMH measurement with knowledge of whether treatment will include a taxane in anthracycline/ cyclophosphamide-based chemotherapy also provides good prediction of long-term ovarian function. These analyses will help inform treatment decisions regarding adjuvant endocrine therapy and the need for adding ovarian suppression to an $\mathrm{AI}$ in women who were premenopausal before starting chemotherapy.

Acknowledgements We are grateful to Roche Diagnostics for the supply of immunoassay materials. Roche had no role in the design, analysis, or interpretation of the study.

Funding This work was undertaken in part in the MRC Centre for Reproductive Health, (supported by MRC Grant MR/N022556/1).

\section{Declarations}

Conflict of interest RAA has undertaken consultancy work for Ferring Pharmaceuticals, Roche Diagnostics, Merck, IBSA, NeRRE Therapeutics and Sojournix Inc. FC has undertaken consultancy work for Merck, BMS, Astra Zeneca, Lilly, Roche. Research funding (institution): Astra Zeneca and Roche. ML has undertaken consultancy work for Roche, Lilly, AstraZeneca and Novartis; and has received speaker honoraria from Takeda, Roche, Lilly, Pfizer, Sandoz and Novartis. The other authors report no potential conflicts of interest.

Open Access This article is licensed under a Creative Commons Attribution 4.0 International License, which permits use, sharing, adaptation, distribution and reproduction in any medium or format, as long as you give appropriate credit to the original author(s) and the source, provide a link to the Creative Commons licence, and indicate if changes were made. The images or other third party material in this article are included in the article's Creative Commons licence, unless indicated otherwise in a credit line to the material. If material is not included in the article's Creative Commons licence and your intended use is not permitted by statutory regulation or exceeds the permitted use, you will need to obtain permission directly from the copyright holder. To view a copy of this licence, visit http://creativecommons.org/licenses/by/4.0/.

\section{References}

1. F Cardoso S Kyriakides S Ohno F Penault-Llorca P Poortmans IT Rubio S Zackrisson E Senkus 2019 Early breast cancer: ESMO clinical practice guidelines for diagnosis, treatment and follow-up Ann Oncol 3011941220 https://doi.org/10.1093/annonc/mdz173

2. Early Breast Cancer Trialists' Collaborative G M Dowsett JF Forbes R Bradley J Ingle T Aihara J Bliss F Boccardo A Coates RC Coombes J Cuzick P Dubsky M Gnant M Kaufmann L Kilburn F Perrone D Rea B Thurlimann C Velde van de H Pan R Peto C Davies R Gray 2015 Aromatase inhibitors versus tamoxifen in early breast cancer: patient-level meta-analysis of the randomised trials Lancet 38613411352 https://doi.org/10.1016/ S0140-6736(15)61074-1

3. A Guerrero J Gavila E Folkerd B Ortiz F Martinez A Garcia MA Climent V Guillem A Ruiz 2013 Incidence and predictors of ovarian function recovery (OFR) in breast cancer (BC) patients with chemotherapy-induced amenorrhea (CIA) who switched from tamoxifen to exemestane Ann Oncol 24674679 https://doi.org/ 10.1093/annonc/mds464

4. IEG Hellemond van IJH Vriens PGM Peer ACP Swinkels CH Smorenburg CM Seynaeve MJC Sangen van der JR Kroep H Graaf de AH Honkoop FLG Erdkamp FWPJ Berkmortel van den JJEM Kitzen M Boer de WK Roos de SC Linn ALT Imholz VCG Tjan-Heijnen 2017 Ovarian function recovery during anastrozole in breast cancer patients with chemotherapy-induced ovarian function failure JNCI J Natl Cancer Inst https://doi.org/10.1093/jnci/ djx074

5. RC Stein M Dowsett A Hedley JC Gazet HT Ford RC Coombes 1990 The clinical and endocrine effects of 4-hydroxyandrostenedione alone and in combination with goserelin in premenopausal women with advanced breast cancer Br J Cancer 62679683

6. PA Francis O Pagani GF Fleming BA Walley M Colleoni I Lang HL Gomez C Tondini E Ciruelos HJ Burstein HR Bonnefoi M Bellet S Martino CE Geyer Jr MP Goetz V Stearns G Pinotti F Puglisi S Spazzapan MA Climent L Pavesi T Ruhstaller NE Davidson R Coleman M Debled S Buchholz JN Ingle EP Winer R Maibach M Rabaglio-Poretti B Ruepp A Leo Di AS Coates RD Gelber A Goldhirsch MM Regan Soft, Investigators T The International Breast Cancer Study G 2018 Tailoring adjuvant endocrine therapy for premenopausal breast cancer N Engl J Med 379 122137 https://doi.org/10.1056/NEJMoa1803164

7. F Perrone M Laurentiis De S Placido De M Orditura S Cinieri F Riccardi AS Ribecco C Putzu L Mastro Del E Rossi V Tinessa AM Mosconi F Nuzzo F Rella Di A Gravina G Iodice G Landi C Pacilio V Forestieri R Lauria A Fabbri T Ibrahim E Maio De S Barni S Gori V Simeon L Arenare G Daniele MC Piccirillo N Normanno A Matteis de C Gallo 2019 Adjuvant zoledronic acid and letrozole plus ovarian function suppression in premenopausal breast cancer: HOBOE phase 3 randomised trial Eur J Cancer 118 178186 https://doi.org/10.1016/j.ejca.2019.05.004

8. ESHRE Guideline Group on Female Fertility Preservation RA Anderson F Amant D Braat A D'Angelo SM Chuva de Sousa Lopes I Demeestere S Dwek L Frith M Lambertini C Maslin M Moura-Ramos D Nogueira K Rodriguez-Wallberg N Vermeulen 2020 ESHRE guideline: female fertility preservation Hum Reprod Open https://doi.org/10.1093/hropen/hoaa052

9. M Lambertini FA Peccatori I Demeestere F Amant C Wyns JB Stukenborg S Paluch-Shimon MJ Halaska C Uzan J Meissner M Wolff von RA Anderson K Jordan EG Committee 2020 Fertility preservation and post-treatment pregnancies in post-pubertal cancer patients: ESMO clinical practice guidelines Ann Oncol 31 16641678 https://doi.org/10.1016/j.annonc.2020.09.006

10. MH Jacobson AC Mertens JB Spencer AK Manatunga PP Howards 2016 Menses resumption after cancer treatment-induced 
amenorrhea occurs early or not at all Fertil Steril 105765772. e764 https://doi.org/10.1016/j.fertnstert.2015.11.020

11. M Lambertini HCF Moore RCF Leonard S Loibl P Munster M Bruzzone L Boni JM Unger RA Anderson K Mehta S Minton F Poggio KS Albain DJA Adamson B Gerber A Cripps G Bertelli S Seiler M Ceppi AH Partridge L Mastro Del 2018 Gonadotropinreleasing hormone agonists during chemotherapy for preservation of ovarian function and fertility in premenopausal patients with early breast cancer: a systematic review and meta-analysis of individual patient-level data J Clin Oncol 3619811990 https://doi. org/10.1200/JCO.2018.78.0858

12. M Lambertini E Blondeaux F Perrone L Mastro Del 2020 Improving adjuvant endocrine treatment tailoring in premenopausal women with hormone receptor-positive breast cancer J Clin Oncol 3812581267 https://doi.org/10.1200/JCO.19.02242

13. D Dewailly CY Andersen A Balen F Broekmans N Dilaver R Fanchin G Griesinger TW Kelsey A Marca La C Lambalk H Mason SM Nelson JA Visser WH Wallace RA Anderson 2014 The physiology and clinical utility of anti-mullerian hormone in women Hum Reprod Update 20370385 https://doi.org/10.1093/ humupd/dmt062

14. JS Finkelstein H Lee A Karlamangla RM Neer PM Sluss SM Burnett-Bowie K Darakananda PK Donahoe SD Harlow SH Prizand H Joffe A Kumar DE Martin D McConnell S Merrilat A Morrison LM Pastore JF Randolph GA Greendale N Santoro 2020 Antimullerian hormone and impending menopause in late reproductive age: the study of women's health across the nation $\mathrm{J}$ Clin Endocrinol Metab 105 e1862 e1871 https://doi.org/10.1210/ clinem/dgz283

15. TW Kelsey P Wright SM Nelson RA Anderson WH Wallace 2011 A validated model of serum anti-müllerian hormone from conception to menopause PLoS ONE 6 e22024 https://doi.org/10.1371/ journal.pone.0022024PONE-D-11-03998[pii]

16. RA Anderson $\mathrm{HI}$ Su 2020 The clinical value and interpretation of anti-mullerian hormone in women with cancer Front Endocrinol (Lausanne) 11574263 https://doi.org/10.3389/fendo.2020.574263

17. RA Anderson APN Themmen A Al Qahtani NP Groome DA Cameron 2006 The effects of chemotherapy and long-term gonadotrophin suppression on the ovarian reserve in premenopausal women with breast cancer Hum Reprod 2125832592

18. A Dezellus P Barriere M Campone C Lemanski L Vanlemmens L Mignot T Delozier C Levy C Bendavid M Debled T Bachelot C Jouannaud C Loustalot MA Mouret-Reynier A Gallais-Umbert D Masson T Freour 2017 Prospective evaluation of serum antimullerian hormone dynamics in 250 women of reproductive age treated with chemotherapy for breast cancer Eur J Cancer 7972 80 https://doi.org/10.1016/j.ejca.2017.03.035

19. T Freour P Barriere D Masson 2017 Anti-mullerian hormone levels and evolution in women of reproductive age with breast cancer treated with chemotherapy Eur J Cancer 7418 https://doi.org/10. 1016/j.ejca.2016.12.008

20. M Lambertini N Olympios J Lequesne C Calbrix M Fontanilles A Loeb M Leheurteur I Demeestere F Fiore Di A Perdrix F Clatot 2019 Impact of taxanes, endocrine therapy, and deleterious germline BRCA mutations on anti-mullerian hormone levels in early breast cancer patients treated with anthracycline- and cyclophosphamide-based chemotherapy Front Oncol 9575 https://doi. org/10.3389/fonc. 2019.00575

21. RA Anderson DA Cameron 2011 Pretreatment serum anti-mullerian hormone predicts long-term ovarian function and bone mass after chemotherapy for early breast cancer J Clin Endocrinol Metab 9613361343 https://doi.org/10.1210/jc.2010-2582

22. RA Anderson M Rosendahl TW Kelsey DA Cameron 2013 Pretreatment anti-mullerian hormone predicts for loss of ovarian function after chemotherapy for early breast cancer Eur J Cancer 4934043411 https://doi.org/10.1016/j.ejca.2013.07.014
23. A Barnabei L Strigari P Marchetti V Sini L Vecchis De SM Corsello F Torino 2015 Predicting ovarian activity in women affected by early breast cancer: a meta-analysis-based nomogram Oncologist 2011111118 https://doi.org/10.1634/theoncologist. 2015-0183

24. KJ Ruddy A O'Neill KD Miller BP Schneider E Baker JA Sparano C Dang DW Northfelt GW Sledge Jr AH Partridge 2014 Biomarker prediction of chemotherapy-related amenorrhea in premenopausal women with breast cancer participating in E5103 Breast Cancer Res Treat 144591597 https://doi.org/10.1007/ s10549-014-2891-0

25. C Xue W Wei P Sun W Zheng X Diao F Xu J Huang X An W Xia R Hong K Jiang R Huang Z Yuan S Wang A Li R Zou Y Shi 2019 Pretreatment anti-mullerian hormone-based nomogram predicts menstruation status after chemotherapy for premenopausal women with hormone receptor-positive early breast cancer Breast Cancer Res Treat 173619628 https://doi.org/10.1007/ s10549-018-4997-2

26. HC Su C Haunschild K Chung S Komrokian S Boles MD Sammel A DeMichele 2014 Prechemotherapy antimullerian hormone, age, and body size predict timing of return of ovarian function in young breast cancer patients Cancer 12036913698 https://doi. org/10.1002/cncr.28942

27. RA Anderson J Mansi RE Coleman DJA Adamson RCF Leonard 2017 The utility of anti-mullerian hormone in the diagnosis and prediction of loss of ovarian function following chemotherapy for early breast cancer Eur J Cancer 875864 https://doi.org/10. 1016/j.ejca.2017.10.001

28. J Chai AF Howie DA Cameron RA Anderson 2014 A highlysensitive anti-mullerian hormone assay improves analysis of ovarian function following chemotherapy for early breast cancer Eur J Cancer 5023672374 https://doi.org/10.1016/j.ejca.2014.06.011

29. HA Kim J Choi CS Park MK Seong SE Hong JS Kim IC Park JK Lee WC Noh T Ati 2018 Post-chemotherapy serum anti-mullerian hormone level predicts ovarian function recovery Endocr Connect 7949956 https://doi.org/10.1530/EC-18-0180

30. FY Vos De HW Laarhoven van JS Laven AP Themmen LV Beex CG Sweep C Seynaeve A Jager 2012 Menopausal status and adjuvant hormonal therapy for breast cancer patients: a practical guideline Crit Rev Oncol Hematol 84252260 https://doi.org/10. 1016/j.critrevonc.2012.06.005

31. W Rosner SE Hankinson PM Sluss HW Vesper ME Wierman 2013 Challenges to the measurement of estradiol: an endocrine society position statement J Clin Endocrinol Metab 9813761387 https://doi.org/10.1210/jc.2012-3780

32. BE Bertelsen R Kellmann K Viste AT Bjornevik HP Eikesdal PE Lonning JV Sagen B Almas 2020 An ultrasensitive routine LC-MS/MS method for estradiol and estrone in the clinically relevant sub-picomolar range J Endocr Soc https://doi.org/10.1210/ jendso/bvaa047

33. HA Kim JW Lee SJ Nam BW Park SA Im ES Lee YS Jung JH Yoon SS Kang SJ Lee KH Park J Jeong SH Cho SY Kim LS Kim BI Moon MH Lee TH Kim C Park SH Jung G Gwak J Kim SH Kang YW Jin HJ Kim SH Han W Han MH Hur WC Noh Korean Breast Cancer Study G 2020 Adding ovarian suppression to tamoxifen for premenopausal breast cancer: a randomized phase III trial J Clin Oncol 38434443 https://doi.org/10.1200/JCO.19. 00126

34. ESHRE Guideline Group on POI L Webber M Davies R Anderson J Bartlett D Braat B Cartwright R Cifkova K-S Muinck de E Hogervorst F Janse L Liao V Vlaisavljevic C Zillikens N Vermeulen 2016 ESHRE guideline: management of women with premature ovarian insufficiency Hum Reprod 31926937 https://doi.org/ 10.1093/humrep/dew027

35. SD Harlow M Gass JE Hall R Lobo P Maki RW Rebar S Sherman PM Sluss TJ Villiers de Group SC 2012 Executive summary of 
the stages of reproductive aging workshop +10 : addressing the unfinished agenda of staging reproductive aging J Clin Endocrinol Metab 9711591168 https://doi.org/10.1210/jc.2011-3362

36. N Panay RA Anderson RE Nappi AJ Vincent S Vujovic L Webber W Wolfman 2020 Premature ovarian insufficiency: an International Menopause Society White Paper Climacteric 23426446 https://doi.org/10.1080/13697137.2020.1804547
Publisher's Note Springer Nature remains neutral with regard to jurisdictional claims in published maps and institutional affiliations. 